\title{
VERDAD Y LIBERTAD EN KIERKEGAARD
}

\author{
JoAn Caravedo
}

Pontificia Universidad Católica del Perú

Resumen: El texto propone una aproximación introductoria a la relación entre libertad y verdad. Para lograr esto seguirá una ruta, amparada fundamentalmente en el texto de Kierkegaard Migajas filosóficas, que comenzará con el problema socrático en torno a la adquisición de la verdad, pasando a considerar la dación de la verdad fruto del amor gratuito de Dios, desde el cual habrá de emerger el tema de la libertad que, por último, terminará por conducirnos a la explicación kierkegaardiana del devenir $\mathrm{y}$, específicamente, al tema de la relación entre posibilidad y realidad. En esta exposición, el concepto que procurará articular todo nuestro recorrido será el de instante, entendiendo este como punto de confluencia entre lo eterno y lo temporal y resaltando la paradoja aquí implicada.

Palabras clave: Kierkegaard, instante, libertad, condición, verdad.

Abstract: This paper proposes an introduction to the Kierkegaardian relation between freedom and truth. In order to do this, mainly paying attention to his Philosophical Fragments, it begins with the Socratic problem of acquiring truth. After this, it focuses on truth as the fruit of God's free love, whence emerges the topic of freedom. Finally, this theme leads to the Kierkegaardian account of becoming, and specifically to the relation between possibility and reality. Throughout this exposition, the central concept that articulates this itinerary is the "instant", understanding it as the point of convergence between the eternal and the temporal, stressing the paradox therein.

Keywords: Kierkegaard, instant, freedom, condition, truth. 
"iEs lícito vagar incesantemente y detenerse donde anochezca?"

Søren, Kierkegaard, Migajas filosóficas ${ }^{321}$

El tema que indagaré, en torno al tópico de la paradoja, es el de la relación entre libertad y verdad. Para lograr esto seguiré una ruta, amparado, fundamentalmente, en el texto Migajas filosóficas, que comenzará con el problema socrático en torno a la adquisición de la verdad, pasando a considerar la dación de la verdad fruto del amor gratuito de Dios, desde el cual habrá de saltar el tema de la libertad que, por último, terminará por conducirnos a la explicación kierkegaardiana del devenir y, específicamente, al tema de la relación entre posibilidad y realidad. En todos ellos, la paradoja aparecerá, sobre todo, concentrada en la relación peculiar que nuestro autor procura establecer entre eternidad y tiempo, cuya intersección él ubica en el instante.

Comencemos, entonces, con aquello que podríamos llamar la vía "socrática" kierkegaardiana. Se puede anotar a modo de sugerencia que conocer a Kierkegaard es conocer a muchas personas, y que cada una de estas involucra un acceso distinto a su problemática filosófica personal. Todas son vías y remiten, al final, a un único sentido. Y, no obstante, cada una implanta una propia cadencia y ritmo, y atañe, con ello, a muy peculiares disposiciones o elecciones de vida.

La vía socrática, entonces, tiene su propio acceso y, en cuanto socrática, no puede dejar de seguir el camino de Sócrates. Así como el Sócrates platónico da cuenta de su dialéctica en La República, como un tomar un supuesto e ir ascendiendo de supuesto en supuesto hacia lo ya no supuesto, Kierkegaard tomará aquí como supuesto la propia teoría socrática para ir desde ella a lo ya no supuesto. Saltar más allá de Sócrates debe hacerse por la vía socrática; asumiremos lo socrático y un elemento extrínseco a lo propiamente socrático. De este modo, instauramos la posibilidad de una superación que, no obstante, mantenga dentro de sí aquello que se procura superar. Esta formulación no debería dejarnos de alertar sobre un guiño hegeliano; aunque, como veremos,

321 Kierkegaard, Søren, Migajas filosóficas o un poco de filosofía, Madrid: Trotta, 1997, p. 68. En adelante MF. 
Kierkegaard preponderará la tensión antes que la resolución. Este movimiento dialéctico, entonces, habrá de remitirnos a un estrato donde lo que acontezca sea, más allá de esta superación-conservadora, la necesidad de reafirmar lo paradójico (es decir, la afirmación de dos términos irreconciliables yen tensión).

Aquello que consideraremos como lo propiamente socrático es el problema de la adquisición de la verdad. Este problema no es otro que el que presenta Menón, en el diálogo platónico homónimo, que está enfocado precisamente en el tema de la virtud ${ }^{322}$. Dicho problema estriba, más que en la verdad misma y en su búsqueda, en las condiciones mismas de la búsqueda de la verdad. El problema de Menón se funda, así, en dar cuenta de qué es lo que requeriríamos para lograr hallar la verdad. Caemos en cuenta de que lo requerido para buscar la verdad es conocerla previamente, puesto que, de otro modo, parecería absurdo buscar aquello que no se conoce ${ }^{323}$. Si esto es el caso, si ya conocemos la verdad, salta a la vista que nos encontramos con un problema: para qué buscamos la verdad si ya la conocemos ${ }^{324}$. El problema planteado por Menón parte de que la condición para la verdad coincide con la verdad misma; $y$, justamente porque esta coincidencia acontece, podemos decir que nos encontramos ante una situación paradójica. Se afirme o niegue la posesión de la condición de la verdad, entonces el conocimiento mismo de la verdad deviene superfluo. En búsqueda de salvar el problemay eludir esta situación paradójica, Platón introduce la doctrina de la reminiscencia: la verdad ya se posee, no podemos eludir esto, pero hace falta recordarla, traerla a la luz, ayudarla en su alumbramiento ${ }^{325}$. La reminiscencia, entonces, instituye una asimetría, no entre el conocimiento de la verdad y su condición (lo que no podría seguirse, a menos que afirmemos que la condición supuesta por la verdad es una noverdad, lo que es absurdo), sino entre el conocimiento y el recuerdo de dicho conocimiento. Conocer algo no implica recordarlo, aunque la condición del recuerdo sea el conocerlo previamente. Los supuestos que tomaremos de Sócrates, con Kierkegaard, serán la necesidad de que solo hay verdad si hay condición y la identidad entre condición y condicionado. No aceptaremos, empero, la asimetría entre conocimiento y recuerdo que impone la doctrina de

322 Cf. Platón, Menón, 80c-80d.

323 "La condición para comprender la verdad es la misma que para poder interrogar sobre ella” (Kierkegaard, Søren, MF, p. 31).

324 Cf. ibid., p. 27.

I46 325 Cf. Platón, op. cit., 8 lal0 ss. 
la reminiscencia. Motivo por el cual se podrá ir anticipando de dónde proviene el elemento no socrático que mantendrá la relación paradójica.

La condición para la verdad debe darse, puesto que de lo contrario no podríamos hacernos con la verdad. El problema está, entonces, en considerar cuándo es que dicha condición se da. Incluso la noción de reminiscencia implica esta introducción de la anterioridad del conocimiento, es decir, la prefiguración de un cuándo se da la condición. El problema de la verdad se torna, entonces, un problema de relación entre verdad y tiempo (a lo que aludíamos con el cuándo). La respuesta platónica, la de la reminiscencia, sabemos, se sostiene en la inmortalidad del alma. Con ello, la respuesta a cuándo tenemos la condición resulta ser que siempre la hemos tenido. La verdad pasa a tomar plaza en lo eterno y lo temporal; podríamos decir que queda en el inhóspito páramo de la no-verdad. Que la verdad se dé en este o aquél momento es irrelevante frente a la verdad que, eternamente, desde la inmortalidad supuesta, se había poseído. Lo que ocurra en el momento en el que acaece el recuerdo de la verdad será solo ocasión para traer aquí la verdad ya poseída y salvar la asimetría que instituye la memoria.

Pero, contra este recurso de apelar a una asimetría que mantenga aislada la verdad del tiempo, nos encontramos nosotros, hombres en el tiempo, viviendo cada instante y haciéndonos de la verdad en nuestra situación concreta: haciendo a la verdad verdadera en cuanto interiorizamos dicha verdad. Lo fundamental para Kierkegaard es este instante de adquisición de la verdad. Nuestro problema se transfigura a partir de esta nueva pauta. Resulta absurdo pensar una verdad eterna que no se dé en el tiempo, o, expresado de otra manera: la más absoluta verdad objetiva requiere ser creíble para consumar su verdad (lo que calza perfectamente con la noción kierkegaardiana de que la verdad es subjetividad). Y parecería paradójico (de hecho lo es) que lo eterno de la verdad (lo atemporal) se dé en el tiempo. Lo maravilloso de la consideración temporal kierkegaardiana es que, en este aspecto, lo eterno y lo temporal se reúnen, lo que de alguna manera da pie a la intuición de que éste presente absoluto, el instante en el que se adquiere la verdad, confluye, como sustrayéndose de la temporalidad, con lo eterno.

En esta tensión paradójica que mantiene a lo temporal y a lo eterno, se anuncia ya aquello que dará propiamente la condición de la verdad en Kierkegaard, 
cuya formulación podría ser la siguiente: Dios surge en el instante. Quede, en todo caso, absolutamente claro que el proyecto de pensamiento de este autor va por ese rumbo, a saber, lograr mostrar que "lo eterno, que no existía antes, [ha] nacido en ese instante" ${ }^{26}$. Así, "mientras todo el pathos griego se concentra en la reminiscencia, el pathos de nuestro proyecto se concentra en el instante" 327 .

Aceptemos, con Kierkegaard, que el instante es fundamental y que, asimismo, en dicho instante se nos brinda la condición. Con este giro, que ha partido de Sócrates y que ha introducido un supuesto no socrático, nos vemos indudablemente remitidos a un sinfín de cuestiones. Podríamos comenzar indagando en torno a cómo es que el instante puede llegar a ser el momento en el que se da la condición o, mejor dicho, qué implica el que la condición sea dada en el instante. Podríamos pensar, que tal como el maestro socrático ayuda a alumbrar la verdad, es el maestro quien brinda en el instante la condición. Esto es imposible, empero: el que enseña supone ya al discípulo dispuesto para la verdad, pero no puede brindarle la condición para la verdad ${ }^{328}$. De lo contrario, o bien supondríamos que la verdad es una determinación extrínseca al sujeto, y tendríamos que volver por el camino socrático a afirmar la reminiscencia, - bien deberíamos asumir que el discípulo ya poseía de antemano la verdad y que, con ello, el maestro solo ayuda a su alumbramiento (y de nuevo retornaríamos a Sócrates). El discípulo mismo tampoco podrá darse la condición. De lo contrario, en cuanto la condición de la verdad y la verdad coinciden, el discípulo estaría ya en la verdad (nuevamente, deberíamos incorporar una condición de asimetría de la verdad y volveríamos al camino de Sócrates) ${ }^{329}$. De ser este el caso, ninguno de los hombres puede otorgar la condición y, con ello, la condición habrá de tener un origen extrahumano, digamos, divino.

Los hombres nos encontramos, hasta el instante, fuera de la verdad (en la no-verdad) y es Dios quien nos da la condición para la verdad y, en cuanto brinda la condición, brinda la verdad misma (recordemos que entre condición y verdad no media distinción alguna, a no ser que recurramos a establecer una

326 Kierkegaard, Søren, MF, p. 30.

327 lbid., p. 36.

328 “Toda enseñanza se funda, en definitiva, en que la condición esté presente" (ibid., p. 3I).

329 "Si el instante ha de tener importancia decisiva (y si no se acepta esto, nos anclamos en lo socrático) el discípulo ha de estar sin condición e incluso despojado de ella" (ibid.). 
asimetría en el tiempo). El instante se convierte así en el punto de salto desde la no-verdad hacia la verdad. Esta relación que se establece entre este salto y Dios es, por lo demás, interesante. Por un lado, porque ella nos conduce a preguntarnos qué es aquello que hace que Dios nos brinde la verdad. Por otro lado, porque, en cuanto es Dios el que nos brinda la verdad en el instante, cabe preguntar de inmediato icómo es que nos encontramos fuera de ella de modo que sea en el instante en el que la recuperemos?

Si seguimos el primer derrotero, es decir, si preguntamos por qué Dios nos brinda la condición, arribamos a un punto fundamental: el amor. Es evidente que ninguna otra razón podría hacer que Dios, quien ha creado todo y que nada debe a las creaturas, les ofrezca a ellas alguna gracia. Solo en cuanto ama, ofrece una gracia libremente y sin pedir nada a cambio. Dios adquiere una caracterización muy particular en la óptica kierkegaardiana. Aceptado que es en un acto amoroso en el que Dios nos brinda la condición, caemos en cuenta de cómo es que se presenta este Dios amoroso. Para ello, requerimos aceptar con Kierkegaard que "en el amor se iguala lo diferente"330. Tal como podemos nosotros vivir el amor, solo lo podemos vivir en tanto se instaura una igualdad. Un amor donde uno de los miembros se considera inferior o superior no es, pues, amor, sino, en todo caso, admiración o asistencia. Ahora bien, por otra parte, el amor supone siempre la libertad. Con esto, toda posibilidad de correspondencia amorosa no solo supone la igualdad, sino también la libertad del ser amado que responde al amor con amor ( $y$, con ello, plenifica la relación amorosa). No existe algo así como el amor por obligación. Dios, en cuanto nos ama, tiene que habernos creado libres para amarlo: "si su amor era la causa, el amor ha de ser también la meta" ${ }^{331}$, afirma Kierkegaard. Dios en su libertad nos crea libres para corresponderle en el amor y, justo aquí, donde Dios siente la posibilidad de la igualdad del amor, siembra también una paradoja: la posibilidad de no corresponder a dicho amor debido a la propia libertad que el amor supone. Dios, al amar al hombre, deja tener un puesto indiferente y se vuelve un Dios dolido, un Dios sufriente ${ }^{332}$. Dolido por amor, porque en la posibilidad del amor -la libertad-estriba también la posibilidad de que no se plenifique la relación amorosa. En el amor de Dios, vuelve a

330 Ibid., p. 4I.

331 Ibid.

332 Cf. ibid., p. 43. 
acontecer la paradoja. Se debe ver, en todo caso, cómo es que este amor gratuito, que brinda la condición, brinda también la libertad. De este modo, veremos quizá que entre condición y libertad no media diferencia alguna. Pero vayamos a nuestro segundo problema.

Nuestro segundo problema era: icómo es que nos encontramos fuera de la verdad? Asimismo, tenemos que considerar un elemento más: ¿cómo nos encontramos fuera de la verdad si Dios nos ama? Dios da la condición y la verdad en un acto de gratuito amor; por ello, sería absurdo que él mismo nos negara la participación en dicha condición: "Dado que el discípulo está en la no-verdad y que está ahí por sí mismo (...), podría parecer que era libre, pues la libertad consiste en ser sí mismo. No obstante, está cautivo, encadenado y encerrado, porque ser libre para la verdad es estar encerrado, y estar encerrado en sí mismo equivale a estar encadenado. Pero si está encadenado a sí mismo, ¿no podrá desatarse por sí mismo ni liberarse? Ya que lo mismo que me encadena, podría liberarme cuando quisiera, y habiendo sido él, también él mismo lo lograría. Ante todo tendría que quererlo"333.

En estas líneas Kierkegaard hace un movimiento fundamental que nos permite dar un salto. Asumamos, entonces, como se ha venido afirmando, que el discípulo está en la no-verdad. Asumamos, además, que dicha no-verdad, su falta de condición o disposición, no ha podido venir de Dios, pues consideraremos a Dios como aquel principio que supera lo humano y que, con ello, puede otorgar la condición (ni el maestro ni el discípulo podrían tenerla, según vimos). Dado esto, la no-verdad del discípulo habrá tenido que venir, necesariamente, de él mismo, pero, en cuanto es él mismo en su aislamiento, sin que pueda haber otro principio determinante externo. El aislamiento del sujeto de todas sus condiciones externas resulta en la libertad. Solo, en cuanto no está determinado, el hombre es libre. Si este es el caso, y la condición para la verdad se recibe mediante el ejercicio de la libertad otorgada gratuitamente por Dios, entonces debe haber sido por esta misma libertad por la que el discípulo ha elegido perder la condición. Del mismo modo que la relación amorosa con Dios se frustra por aquello que está supuesto en ella -a saber, la libertad-, la condición por la que poseemos la verdad se frustra 
por ella misma. Acerquémonos, a partir del pasaje propuesto, a esta tensión paradójica encontrada.

Comprendido esto así, se podrá ver la peculiaridad de la postura de Kierkegaard, que se ampara en una tensión que se expresa en: "ser libre para la verdad es estar encerrado". La verdad y la libertad se oponen; y esto se hace patente cuando atendemos a los conceptos asociados a estos dos elementos. Así, por el lado de la verdad, nos encontramos con la necesidad y la eternidad; mientras que, por el lado de la libertad, se desprenderían conceptos como el de contingencia y el de temporalidad. Dentro de esta díada supuesta comprendemos, por una parte, que el origen de la no-verdad ha de estar en la libertad, es decir, ahí donde la contingencia y la temporalidad resultan ineludibles. La no-verdad en la que se encuentra el discípulo ha de ser una elección, un estar dispuesto a algo, una libre determinación. Demos esta elección de la no-verdad por sentada.

Y en un giro, no obstante, Kierkegaard nos deja entender que si el hecho de estar en la no-verdad parte de la libertad, entonces el poder que instituye esa libertad y que encadena, también podría, en tanto poder, liberarnos. Es, entonces, un acto del querer, de aplicación de la libertad, lo que me ata y desata. La libertad que se constituía como el otro extremo de la verdad es, entonces, lo mismo que la verdad. La verdad es subjetividad. Acontece, entonces, nuevamente la paradoja. Cabe ahora preguntar cómo es que acontece este cambio, producto de la libertad, desde la no-verdad hacia la verdad, o, para ser más precisos: cómo deviene la no-verdad en verdad. Esto, asimismo, debería darnos algunas luces acerca del vínculo que aquí trazamos, precariamente, entre libertad y verdad.

Kierkegaard afirma que "todo devenir acontece por libertad (...). Todo deviene por una causa. Toda causa culmina en una causa libremente actuante"334. Asimismo, después de aceptado esto, podemos preguntar: ¿qué implica el propio concepto de devenir en Kierkegaard, habida cuenta de que a nosotros nos concierne puntualmente el devenir desde la ausencia de la condición hacia su adquisición? Lo interesante del devenir en Kierkegaard es que este no 
supone un cambio en la esencia, sino en el ser, en la existencia ${ }^{335}$. Aquello que cambia no cambia en relación a lo que es, sino que cambia con relación a si es. El devenir no es un cambio de ser-algo a ser-otra-cosa, lo que representaría un cambio propiamente esencial, sino que es un cambio desde el no-ser al ser. Si el cambio fuera esencial, afirma Kierkegaard ${ }^{336}$, entonces no habría posibilidad de afirmar que algo deviene, porque en el momento en que el devenir iniciara, eso que devenía, pasaría a ser ya otra cosa. En ese sentido, nada devendría. Ahora bien, si afirmamos que el devenir es un cambio del noser al ser, por lo cual lo que deviene se mantiene y cambia, entonces parece que hemos de afirmar inevitablemente que ese no-ser es algo; algo que se mantiene en su tránsito desde el no-ser al ser. Este no-ser, decimos, tiene que ser. "Este ser que es no-ser es la posibilidad"337.Y aquí encontramos un contraste preciso entre realidad y posibilidad; porque, justamente, la posibilidad es un no-ser frente a aquello que es realmente. Esto, por ejemplo, nos permitiría afianzar las conexiones profundas y evidentes entre, por ejemplo, Heidegger y Kierkegaard ${ }^{338}$. El devenir se constituye como un paso desde la posibilidad a la realidad ${ }^{339}$.

Tenemos, con lo dicho, un cuadro general de aquello que nos habíamos propuesto exponer, a saber, la relación entre verdad y libertad. La libertad funda el tránsito de la no-verdad a la verdad, que ahora aparece como un tránsito desde la posibilidad hacia la realidad. Dicho tránsito acontece, además, en el instante; instante que es el lugar de cruce de lo eterno y lo temporal; es el lugar más propio de la paradoja. En este sentido, Dios, en Kierkegaard, puede perfectamente considerarse como la posibilidad que se da en la realidad temporal en cada instante, darse que acontece por obra de nuestra propia libertad. La libertad nos brinda, entonces, la condición -así como la niega (y esto, tras lo dicho, debería parecernos como natural)-, en cuanto ella es la que permite remitirnos a lo siempre posible y traerlo a la realidad.

335 Cf. ibid., p. 82.

336 Cf. ibid., pp. 81-92.

337 lbid., p. 82.

338 Por ejemplo, cf. Heidegger, Martin, Ser y tiempo, Madrid: Trotta, 2009, §40; Heidegger, Martin, Los conceptos fundamentales de la metafísica: mundo, finitud, soledad, Madrid: Alianza Editorial, 2007, §§32-34. 
Ahora bien, solo dejaré un último concepto sin el cual Kierkegaard, considero, no sería presentado como nos proponíamos. Basta recapitular lo dicho: la libertad fundamenta el tránsito de la posibilidad a la realidad, con ello, podemos decir que la libertad se enfrenta cara a cara con esta posibilidad (el no-ser, Dios) que se realiza en el instante. Ahora bien, la libertad misma es, bien entendida, una posibilidad abierta (posibilidad de elección, por ejemplo). La libertad se enfrenta a la posibilidad, puede ser expresado también como una posibilidad que se enfrenta a la posibilidad: esto, según Kierkegaard, es lo que produce la angustia ${ }^{340}$. La angustia es, entonces, encuentro con el noser, con la nada. Es, con ello, el revelarse de la condición de tránsito desde la no-verdad hacia la verdad. La angustia es, al fin de cuentas, la experiencia de tener que estar constantemente arrojados, en cuanto libres, a lo posible ${ }^{341}$. Esto, sin embargo, deberá quedar así de escuetamente expuesto.

340 Cf. Kierkegaard, Søren, El concepto de angustia, Madrid: Alianza Editorial, 2007, p. 88.

34I Aquí, evidentemente, otra conexión entre Heidegger y Kierkegaard evidente (cf. Heidegger, Martin, Ser y tiempo, §40; cf. Heidegger, Martin, “¿Qué es metafísica?”, en: Hitos, Madrid: Alianza Editorial, 2007, pp. 93-108). 